\title{
DISCURSO, CENTENARIO DE LA FACULTAD DE FILOSOFÍA Y EDUCACIÓN
}

\author{
Amado Alonso García
}


Texto íntegro. Amado Alonso García, Discurso, Anales de la Universidad de Chile, Número conmemorativo del Centenario de la Universidad de Chile, 1943. 


\section{DISCURSO, CENTENARIO DE LA FACULTAD DE FILOSOFÍA Y EDUCACIÓN}

Tengo el señalado honor, junto con mi colega don Francisco Romero, de traer ante esta Honorable Casa de Estudio, los saludos, las felicitaciones y los buenos augurios de las Universidades de Buenos Aires y La Plata, y muy en especial de las Facultades hermanas de Filosofía y Letras y de Humanidades.

En cuanto a mí mismo, permitidme manifestar, además de mi gratitud por vuestra honrosa invitación, otro sentimiento menos ceremonioso y de visita, un gozo de participación personal, aunque modesta, en la obra de estudio y de enseñanza acumulada en estas austeras aulas durante cien años de callada labor por generaciones de autoridades, de profesores y de alumnos. Dos veces he tenido ya el privilegio de actuar en esta honorable Facultad como profesor visitante; y en esos cursos he dejado lo mejor de que soy capaz, y aquí he recogido el más deseable galardón: la estimación y la amistad de mis colegas chilenos, y el que me tengan por uno de entre ellos.

No toméis, pues, a arrogancia el que no me sienta del todo ajeno a este brillante jubileo, y que al hablar me incluya como algo más que un visitante.

Ya celebró Chile en su día y con digna pompa el centenario de su Universidad nacional, y sin embargo ambiciono que este centenario de la Facultad de Filosofía y Educación no sea exclusivamente para nosotros, los humanistas. En esta era de la eficacia y del increíble dominio de la naturaleza por el hombre, es frecuente el sentimiento de condescendencia con que los hombres de las ciencias de la materia miran a las del espíritu. Sólo las matemáticas obtienen su incondicional estimación, porque son la base práctica para su conocimiento cuantitativo y mecanicista de la naturaleza. En la metafísica, en la psicología, en la gnoseología y otras disciplinas filosóficas; en la filología, en la arqueología, en la historia del arte, de la cultura, de los Estados, en la etnografía, en la antropología y las demás ciencias históricas, ven unos conocimientos demasiado imprecisos y vacilantes, cortejados con los de las ciencias físicas, y unas técnicas incomparablemente menos disciplinadas que las suyas.

Hay que admitir en seguida que si son nuestros conocimientos menos seguros y nuestras técnicas menos rigurosas que los de las ciencias de la naturaleza; pero que en modo alguno suponen esos «menos» desventaja o minoría de edad; las ciencias físicas, que tienen como objeto de estudio la materia inerte y la vida, trabajan sobre determinaciones y en busca de nuevas determinaciones, y sólo cuentan con la libertad del objeto como un resto metafísico que cae fuera del foso de sus microscopios. Su avance consiste precisamente en reducir ese resto de indeterminación, extendiendo el conocimiento de las leyes de la necesidad.

Las disciplinas filosóficas e históricas, que tienen como objeto de estudio el espíritu y sus huellas en el transcurso del tiempo, trabajan sobre la libertad, que está en la esencia del espíritu y en busca de los testimonios y productos objetivados de esa esencial libertad; y si también cuentan con determinaciones y necesidades, esas no hacen 
más que condicionar la vida libre del espíritu, como el cauce que el río se va labrando para su propio curso; no son más que la materia cuya resistencia es necesaria para la manifestación del espíritu, así como la luz necesita para hacerse visible chocar con los corpúsculos del aire, y así como el aire es necesario para el vuelo de la paloma.

El objeto científico de las humanidades es el registrar e interpretar el paso del espíritu por la tierra, y el sorprender la autodeterminación de lo que las ciencias físicas llamarían su funcionamiento y que las nuestras llaman su vida (y por supuesto no la vida biológica, sino la vida biográfica).

Esta diferencia substancial entre los objetos de las ciencias de la materia y las ciencias del espíritu hace que nosotros los humanistas sintamos en cada avance nuestras averiguaciones en el mismo instante del triunfo, que nuestra alcanzada verdad es una verdad provisional, pues bastan unos ojos diferentes, con otra decantación de experiencias y con otros ideales, para que las sombras del espíritu formen sobre el suelo de nuestra conciencia una nueva lacería; y esa diferencia también es la que hace que los trabajadores de las ciencias físicas tengan el justificado orgullo de la seguridad de sus conquistas, porque su objeto de estudio resiste incólume una gran variedad de pruebas y contrapruebas sin quebranto de la interpretación propuesta.

Pero también los conocimientos de las ciencias físicas son provisionales, aunque duren un poco más. Cada tantos siglos viene un Galileo, un Newton, un Einstein que hace ver la vanidad de los supuesto cimientos y con sólo eso se viene abajo todo el gallardo castillo y hay que levantarlo con nuevas bases y con nueva traza. Estos derrumbes y reconstrucciones ocurren cada vez que un físico de genio siente la necesidad de preguntarse: «¿Qué es esta materia, objeto de nuestro conocimiento?» Ved el antiguo y hermoso atrevimiento de imaginar el átomo, literalmente lo «indivisible». Ved a los físicos modernos asomándose al interior de ese supuesto componente indivisible y revelándonos de pronto dentro de él un nuevo mundo. El átomo es a su vez un compuesto: un electrón y un protón, de cuyo complemento nace la existencia de la materia. Ved a Edington asomándose de nuevo dentro del protón y revelándonos: el protón es a su vez un mundo, una lucha, un drama entre el neutrón y el positrón. Conforme nos van bajando en los pisos y subsuelos de la materia, conforme nos van buscando e identificando los últimos ladrillos del imponente edificio, más fantasmal se va haciendo su sostén material, y la mente se va sintiendo cada vez más centrifugada de los garraderos materiales y disparada por las nieblas espectrales de una pura energía, de un puro suceder, de una pura copulación de espacio-tiempo compuesta de sucesos, como postula Bertrand Russell. Y cuando la física moderna, de componente en componente, llega a vislumbrar como sostén de la materia algo que ya no es materia, una energía, hasta la austera imaginación de los físicos tiene que sobrecogerse y musitar: «hemos dado con los límites del espíritu». También en la inmensidad de las construcciones siderales los físicos van empujando y alejando los límites del saber, y al estudiar tan inconcebibles cantidades de materia y sus leyes musicales de existencia y movimiento, más allá de toda masa y más allá de todo soporte se encuentran con una energía: también ahí, y desde muy antiguo, vagan los físicos por los linderos del espíritu. Y vagan como ansiosos cazadores al acecho de la última razón. 
Así, pues, la seguridad de los conocimientos físicos sólo se siente verdaderamente cuando se trata de razones antepenúltimas, y más aún en las finas operaciones de medir y de contar como en las descripciones anatómicas o en el peso específico de los distintos cuerpos; pero conforme se ahonda y se aleja hacia lo último, los físicos sienten la misma esencial y salvadora inseguridad que nosotros los humanistas. Los físicos porque dan con el ámbito del espíritu, nosotros porque desde un principio le hemos tomado como objeto central de nuestras disciplinas.

Y aquí es donde nos unificamos, no en la limitación y en el fracaso, sino en la hazaña común e inmarcesible de buscar el saber más allá de las determinaciones y de las leyes de la necesidad; en la hazaña de buscarlo ahincadamente, a pesar de la evidencia íntima de que nuestras conquistas son siempre provisionales, bien convencidos desde un comienzo de que los conocimientos científicos que hemos levantado después de resquebrajar o de reducir a escombros los conocimientos anteriores, serán a su turno resquebrajados y finalmente demolidos para la erección de los futuros y mejores conocimientos. Y sabiendo que esto sucederá en los próximos lustros, o si no en los próximos siglos, o si no en los próximos milenios, pero inexorablemente y para bien de la ciencia.

Cierto que esta valerosa renunciación no naufraga del todo nuestra humana ansia de valide personal, porque también vivimos la evidencia de estar participando en una apasionante carrera de relevos en la que nos pasamos de mano en mano una antorcha inextinguible. La antorcha no tanto del saber, cuando la del ansia de saber más, la voluntad humana de ir arrancando sus secretos al misterio. Y iqué importa la fugacidad de nuestras conquistas, qué importa si, a medida que nosotros avanzamos, va el misterio alejando sus intangibles murallas, cuando vemos lo esencial de toda ciencia en el tesón humano de averiguar?

Un período chileno de este invencible tesón humano es el que estamos celebrando con las fiestas del centenario de la Facultad de Filosofía y Educación. Y es bueno y confortante detenerse un momento en algunas fechas representativas, es bueno hacer un breve alto en el camino para contemplar el monto de la labor acumulada.

Es bueno y animador. En nada nos acobarda que algunas de las flores del saber que adornaron ufanas estas aulas, se hayan ajado y envejecido; en nada nos acobarda tampoco la convicción de que mucho de nuestra lozanía actual también se marchitará. Adelante, y siempre animosamente; convencidos de que nuestras conquistas algún día caducadas, nuestros sucesores han de sacar nuevas y luminosas conquistas. Adelante en nuestra infinita carrera de relevos, de verdad en verdad provisional, siempre a los alcances de la última e inalcanzable verdad. 